\title{
HPLC-DAD and HPLC-ESI-MS Analysis of Polyphenol-rich Extracts from Mango (Mangifera indica L.), Tommy Atkins and Haden Varieties, Cultivated in Dominican Republic
}

\author{
Alberto Julio Nunez-Selles ${ }^{1,}$, , Victor Manuel Espaillat Martínez ${ }^{1}$, Lauro Nuevas Paz ${ }^{2}$ \\ ${ }^{1}$ Research Division, National Evangelic University (UNEV), Santo Domingo, Dominican Republic \\ ${ }^{2}$ R\&D Department, Laboratories Magnachem, San Cristóbal, Dominican Republic \\ Email address: \\ anunez@unev.edu.do (A. J. Nunez-Selles),nunez500412@gmail.com (A. J. Nunez-Selles), vespaillat@unev.edu.do (V. M. E. Martínez), \\ nuevaspaz@yahoo.es (L. N. Paz) \\ ${ }^{*}$ Corresponding author
}

\section{To cite this article:}

Alberto Julio Nunez-Selles, Victor Manuel Espaillat Martínez, Lauro Nuevas Paz. HPLC-DAD and HPLC-ESI-MS Analysis of Polyphenolrich Extracts from Mango (Mangifera indica L.), Tommy Atkins and Haden Varieties, Cultivated in Dominican Republic. International Journal of Pharmacy and Chemistry. Vol. 6, No. 6, 2020, pp. 77-88. doi: 10.11648/j.ijpc.20200606.12

Received: November 25, 2020; Accepted: December 4, 2020; Published: December 16, 2020

\begin{abstract}
Background: Antioxidant, anti-inflammatory, and analgesic effects of mango stem bark extracts (MSBE) have been reported. A previous published report described the identification of several components (polyphenols, polyols, and sugars) by HPLC, MS, and NMR. Mangiferin (2- $\beta$-D-glucopyranosyl-1,3,6,7-tetrahydroxyl-9H- xanthen-9-one) was identified as the major bioactive component of MSBE. However, MSBE has shown more potent effects than model mangiferin solutions in several in vitro experiments at different concentrations. Therefore, there are other extract components which contribute to the observed pharmacological effects. Objective: The identification of other polyphenolic components in MSBE, which may contribute to the observed pharmacological effects through a synergic pathway. Method: Polyphenol-rich extracts from mango stem bark and branch trees from two varieties (Haden and Tommy Atkins), cultivated in Dominican Republic, were analyzed by HPLC-DAD. Butanol MSBE extract from Haden mango stem bark was analyzed by HPLC-MS-ESI. Results: The mangiferin content in Haden mango extracts by HPLC-DAD was considerably high as compared to previous reports in the literature from other mango varieties. The identification of Haden mango stem bark butanolic extract components by HPLCESI-MS led to the unambiguous identification of 20 components: 2 benzoic acid derivatives, gallic acid and 8 gallate derivatives, 2 benzophenones (maclaurin and iriflophenone types), 3 flavonoids (catechin, epicatechin, and quercetin), mangiferin, isomangiferin, homomangiferin, and noratyriol. Conclusion: HPLC-ESI-MS analysis of the Haden mango SB extract showed the presence of many polyphenolic components, not previously reported, which may correlate to the antioxidant, anti-inflammatory, and/or analgesic effects of this extract mostly through a synergistic effect of its components. The potential exploitation of mango by-products from the Haden variety would be the best option for obtaining polyphenolrich extracts from mango agricultural by-products to be used as bioactive ingredients in nutraceutical, cosmeceutical, and/or pharmaceutical formulations.
\end{abstract}

Keywords: Mangiferin, Mangifera indica, Haden Mango, Tommy Atkins Mango, Stem Bark, Branch Tree, Circular Economy

\section{Introduction}

Mango pulp and juice, besides the fresh fruit commercialization, are the main commercialized products from the mango fruit industry; worldwide fruit production is above 40 million tons being India, China, Pakistan, and
Brazil the main producers [1]. Uses of mango (Mangifera indica L.) extracts with antioxidant properties have been reported extensively in the last two decades and claims about its antioxidant properties have been published [2-4]. Mango fruit processing technologies produce a large amount of wastes, mainly peel and seed. The amount of 
peel and seeds wasted from fruit collection has been estimated between $35 \%$ and $60 \%$, respectively, depending on the region and the variety [5]. In order to assess the potential uses of these wastes, several procedures have been developed to obtain polyphenol-rich extracts from peel and seed kernel [6-9], with an impact on the industrial diversification of mango production, and the reduction of the environmental impact of industrial residues, within the concept of a circular economy. However, studies about the utilization of mango agricultural by-products (leaves, stem bark, and branch trees) for similar goals have not been performed in the same extent. Uses of leaf extracts, mainly aqueous decoctions for ethnomedical uses, have been reported as well as their antioxidant and anti-inflammatory properties [10] Leaves have been studied by several extraction procedures to obtain antioxidant-rich extracts $[11$, 12]. However, little attention has been devoted to the potential exploitation of stem bark (SB), and branch trees (BT) in commercial mango plantations [2].

Our work on mango-derived products has focused mainly on $\mathrm{SB}$, and $\mathrm{BT}$, as agricultural by-products, which are not commonly used as starting raw materials for a possible industrial application. About 40 thousand tons of mangoes are collected annually in Dominican Republic along more than 3,000 ha from 58 varieties [1]. Trees are pruned annually in the autumn season (September-November) and these wastes are left in the field. Moreover, SB may be collected from mango trees throughout the year, and this collection may be repeated in the same tree every 3-4 years [13]. It has been estimated that more than 1,500 tons of mango BT are left in the field, and around 300 tons of mango SB may be collected annually in Dominican Republic. These agricultural by-products have a large content of antioxidant flavonoids and xanthones. Therefore, if these products are processed, leading to standardized polyphenol-rich extracts, with a defined content of flavonoids and xanthones, it may lead to a new source of bioactive ingredients to be used in food, cosmetic, and/or pharmaceutical formulations.

A previous work on the chemical characterization of mango stem bark-butanolic extract [14] led to the identification of mangiferin, 2- $\beta$-D-glucopyranosyl-1,3,6,7tetrahydroxy-9H-xanthen-9-one (MF), as the main component in the polyphenol fraction of mango stem barkbutanolic extract (7\%). That extract has been studied extensively, both pre-clinical and clinical, and MF described as one of the most promising candidates to be developed as a bioactive ingredient to be used in cosmeceutic, nutraceutic or pharmaceutical formulations [15]. However, further studies demonstrated that isolated MF from the extract might be acting as antioxidant through a mechanism involving metal complexes [16]. We studied the major and trace element concentrations in the stem bark of 16 Cuban mango varieties [17], and observed that Se concentration was significantly higher for the Haden variety (Code H01). That result correlated with the antioxidant effect of mango stem bark extract not only to $\mathrm{MF}$, but to Se (and possibly $\mathrm{Cu}$ and $\mathrm{Zn}$ ).
The study of mango SB extract and MF on lipid peroxidation on red blood cells concluded that the extract had a higher protective effect than MF, which could explain that other extract components might be acting through a synergistic effect [18]. Therefore, further studies about chemical composition of the mango SB aqueous extract are needed in the attempts to correlate health effects to chemical components, where polyphenols play a significant role.

We report the polyphenolic characterization of agricultural by-products extracts by HPLC-DAD (stem bark and branch tree) from two mango varieties (Haden, and Tommy Atkins) cultivated in Dominican Republic, in order to demonstrate the potential uses of these by-products as sources of polyphenol-rich ingredients for industrial uses. The HPLCESI-MS analysis of polyphenols from the stem bark of Haden mango butanolic extract, as the most promising variety for industrial exploitation, is also reported for the determination of other phenolic constituents that may contribute to the observed biological activities.

\section{Materials and Methods}

\subsection{Chemicals}

PA and HPLC grade solvents (methanol, n-butanol, acetonitrile, and DMSO) and reagents (acetic acid, formic acid, sodium carbonate, and sodium benzoate) were purchased from J. T. Baker (USA). Folin-Ciocalteau reagent was purchased from Merck (Darmstadt, Germany). Milli-Q system from Millipore (Milford, MA) was used for producing ultrapure water. The following standards were purchased from Sigma-Aldrich Co. (Missouri, USA): gallic acid (97.5\% purity, MW: 170.12, white amorphous solid), methyl gallate (98\% purity, MW: 184.15 , white amorphous solid), propyl gallate (98\% purity, MW: 212.20 , white amorphous solid), benzoic acid (99.5\% purity, MW: 122.12 , white amorphous solid), 3,4-dihydroxybenzoic acid (97\% purity, MW: 154.12, white amorphous solid), (+)-catechin (97\% purity, MW: 290.27, colorless amorphous solid), (-)epicatechin (90\% purity, MW: 290.27, colorless amorphous solid), quercetin (95\% purity, MW: 302.24, colorless amorphous solid), and mangiferin (99\% purity, MW=422.34, white amorphous solid).

\subsection{Plant Material}

The stem bark (SB) was collected, free of biological contamination (fungi), from trees grown in farms located in the Bani (Haden), and Puerto Plata (Tommy Atkins) regions, Dominican Republic, in the autumn season (2018 and 2019), without affecting the ecosystem, according to a Standardized Operational Procedure (SOP). Briefly, bark was marked, with not more than $2 \mathrm{~cm}$ depth, making a rectangle of around 10 $\mathrm{cm}$ width and up to $50 \mathrm{~cm}$ height, depending on the tree size. The bark was separated without damaging the inner part of the stem, with specially designed tools. Bark pieces were cleaned manually from dust and residues, and collected in sealed polystyrene bags, approximately $50 \mathrm{~kg}$ per bag. Bags 
were stored protected from light at room temperature, and transported to the lab within the next 7 days after collection. Voucher specimens were deposited at the Biological Products Archive, National Evangelic University, Santo Domingo, Dominican Republic (Codes: 10228B-Haden-, and 10229BTommy Atkins). The branch trees (BT) were collected, free of biological contamination (fungi), from trees grown in farms located in Azua (Haden), and Bani (Tommy Atkins) regions, Dominican Republic, in the 2018 autumn season, according to a SOP. Briefly, BT were cut and left to dry in the field for 1 week by solar radiation. Dried branches were milled on-site with a crusher and collected in polystyrene sealed bags, approximately $50 \mathrm{~kg}$ per bag. Bags were stored protected from light at room temperature, and transported to the laboratory within the next 7 days after collection. Voucher specimens were deposited at the Biological Products Archive, National Evangelic University, Santo Domingo, Dominican Republic (Codes: 10228T-Haden-, and 10229TTommy Atkins).

\subsection{Sample Preparation}

SB and BT were dried at sunlight for 7 days and subsequently with a hot-air dryer (Thermo Scientific, USA) at $60^{\circ} \mathrm{C}$ for 2 hours. Both samples were milled on mortar grinder (Retsch, Germany, Model RM 200), and packed in vacuum-sealed bags (500 g) until extraction. SB, and BT yields were determined for both dried plant materials.

\subsection{Water Content}

The Water Content (WC) of dried SB and BT plant materials, and dried plant extracts were determined with a moisture analyzer (Radwag, Poland, Model PMR 50) by triplicate, and results expressed as mean value \pm standard error $(\mathrm{p}>0.05)$.

\subsection{Extraction Methods}

$100 \mathrm{~g}$ of milled SB, or BT (maximum 10\% WC) were extracted with a Soxhlet equipment $(1 \mathrm{~L})$ with a mixture of 70:30 methanol: deionized water for 1 hour. Solvent was evaporated under vacuum with a rotary evaporator at $60^{\circ} \mathrm{C}$ (Rotavapor E100, MCR, Israel). The residue was brought to dryness with a dry flow of nitrogen, and extract yield was determined. Five batches for each mango by-product were extracted and yield results expressed as mean value \pm standard error $(\mathrm{p}>0.05)$. The solid extract from the Haden mango stem bark $(1 \mathrm{~g})$ was suspended in $50 \mathrm{~mL}$ distilled water and extracted twice with $25 \mathrm{~mL}$ water-saturated n-butanol. The $\mathrm{n}$ butanol layer was brought into a rotary evaporator, and nbutanol was evaporated under vacuum until a brown solid residue was obtained. Samples for HPLC-ESI-MS analysis were prepared by dissolving $10 \mathrm{mg}$ of the solid extract in DMSO into a $10-\mathrm{mL}$ volumetric flask $(1 \mathrm{mg} / \mathrm{mL})$.

\subsection{Polyphenol Content}

The Polyphenol Content (PPC) of extracts was determined by a modified Folin-Ciocalteu method using a catechin- equivalent standard [14]. Mango extract (1.15 mg) was dissolved in methanol $(2 \mathrm{~mL})$, and the solution was diluted 10 -fold with distilled water. Folin-Ciocalteau reagent $(0.5$ $\mathrm{mL}$ ) was added to the diluted solution followed by $0.5 \mathrm{~mL}$ of sodium carbonate, $100 \mathrm{~g} / \mathrm{L}$ solution. The absorbance was measured at $700 \mathrm{~nm}$ (Thermo Scientific, Genesys 10 spectrophotometer) with a blank sample (water plus reagents) in the reference cell ( $1 \mathrm{~cm}$-depth quartz). Quantification was performed by plotting the absorbance value in a calibration curve of $(+)$ catechin used as standard phenol.

\subsection{Quantitative Determination of Polyphenols}

Single polyphenols in mango SB, and BT extracts were determined by HPLC-DAD analyses with a Young Lin HPLC System (South Korea) equipped with a YL-9110 quaternary pump, YL-9150 autosampler (fitted with a $20 \mu \mathrm{L}$ loop), a YL-9160 diode-array detector (DAD) coupled to a data acquisition and processing system (Clarity software). Column (RP-18, $5 \mu \mathrm{m}, 250$ x 4 mm i.d., Merck, Germany) was placed in a YL-9131 column oven at $30^{\circ} \mathrm{C}$. Solvents were degassed (YL-9101), and injection volume was $20 \mu \mathrm{L}$. Separation was carried out by gradient elution with two solvents $[\mathrm{A}=$ acetic acid $(0.1 \%)$ in water; $\mathrm{B}=$ acetic acid $(0.1 \%)$ in methanol]. The ratio of $\mathrm{A}: \mathrm{B}$ was increasing from 9:1 to $1: 9$ in $35 \mathrm{~min}$ at a flow rate of $1 \mathrm{~mL} / \mathrm{min}$. Detection wavelength was fixed at $278 \mathrm{~nm}$. Gallic acid, methyl gallate, propyl gallate, $(+)$ catechin, (-) epicatechin, mangiferin, and quercetin were identified by the retention times of the chromatograms of the available pure standards with retention times of 4.5, 7.2, 8.4, 11.8, 13.5, 14.6, and 19.6, respectively. Isomangiferin $(\mathrm{RT}=15.0)$ was identified by comparing its retention time and UV spectra with the mangiferin standard, which had isomangiferin as impurity.

\subsubsection{Quantitation}

Quantitation was performed by plotting the integrated peak area into the calibration curve of the corresponding pure standard, except for the unknown (peak 2) and isomangiferin (peak 8), which were calculated by an Internal Normalization Method. All polyphenols were assayed as $(+)$ catechin equivalent.

\subsubsection{Linearity}

Linearity was determined for the seven available pure standards. Linearity of responses was determined with five levels of concentrations $(5,10,15,20$, and $25 \mu \mathrm{g} / \mathrm{mL})$, and three injections for each concentration. A linear correlation coefficient $(\mathrm{r}=0.9998)$ was observed, and the minimun detection limit was $0.18 \mathrm{ng}$, which resulted in a signal-tonoise ratio of $3.5: 1$.

\subsubsection{Reproducibility}

The reproducibility of the injection integration procedure was determined for the seven available standards. Standard solutions were injected 10 times and relative standard deviations of retention times were calculated (gallic acid, $1.5 \%$; methyl gallate, $1.8 \%$; propyl gallate, $1.3 \%$; (+) catechin, $2.1 \%$; (-) epicatechin, $2.0 \%$; mangiferin, $1.2 \%$, and quercetin, 
$1.9 \%$ ). Isomangiferin standard deviation was $1.6 \%$.

\subsection{HPLC-ESI-MS Analysis of Polyphenols}

Polyphenolic composition of Haden mango SB butanol extract was determined through a Thermo Finnigan LCQIon Trap (Thermo Separation, USA) with electrospray ionization. Mass spectra were recorded on negative mode between 50 and 1,500 Da; colision chamber temperature $375^{\circ} \mathrm{C}$; pressure 4.1 bar; dry nitrogen flow as nebulizer, 10 $\mathrm{mL} / \mathrm{min}$, and helium as colision gas. First and second orders fragmentation patterns were recorded at 1.2 , and $1.5 \mathrm{~V}$, respectively. Chromatographic separation was performed on a Waters 600E-HPLC with a RP-18 column, $250 \times 4.5$ $\mathrm{mm}$ (Kromasil, Sweden) at $30^{\circ} \mathrm{C}$. Injection volume was 5 $\mu \mathrm{L}$. Separation was carried out by gradient elution with two solvents $[\mathrm{A}=$ formic acid $(0.1 \%)$ in water; $\mathrm{B}=$ formic acid $(0.1 \%)$ in acetonitrile]. The ratio of $\mathrm{A}: \mathrm{B}$ was increasing from 9:1 to $10: 0$ in $90 \mathrm{~min}$ at a flow rate of $1 \mathrm{~mL} / \mathrm{min}$. Data acquisition and peak integration analysis was performed using XCalibur software.

\subsection{Statistic Analysis}

Data from both varieties, Haden and Tommy Atkins, were analyzed using the statistical programs SPSS 9.0. Nonparametric Friedman test using Wilconxon's pair test was assessed. Mann-Whitney $U$ test was used to estimate statistical differences $(p>0.05)$ between varieties. All data in the tables are expressed as the mean value \pm standard error.

\section{Results and Discussion}

\subsection{Agricultural and Extraction Yields}

Water content from SB was down out from around 50\% to a range between $6.5 \%$ and $8 \%$ with subsequent solar drying and rotary hot air drying. BT, which was allowed to solar drying in the field for a week, was directly submitted to hot air drying due to its low water content (around 10\% WC). BT yields were considerably higher as compared to SB. A significant lower yield of SB was obtained in the Bani farm as compared to the Puerto Plata farm (Table 1).

Table 1. Yields and water content of mango agricultural by-products (stem bark and branch tree) from Haden and Tommy Atkins varieties, after drying.

\begin{tabular}{|c|c|c|c|c|c|c|c|c|c|}
\hline \multirow{2}{*}{ Variety } & \multirow{2}{*}{ Farm location } & \multicolumn{2}{|c|}{ MSB (kg) } & \multirow{2}{*}{ Water (\%) } & \multicolumn{2}{|c|}{ MBT (kg) } & \multirow{2}{*}{ Water (\%) } & \multicolumn{2}{|c|}{ Yield (\%) } \\
\hline & & Field & Dried & & Field & Dried & & MSB & MBT \\
\hline \multirow{2}{*}{ Haden } & Azua & - & - & - & 280 & 248 & $5.2 \pm 0.5$ & - & 88 \\
\hline & Bani & 530 & 245 & $6.5 \pm 0.8$ & - & - & & 46 & - \\
\hline Tommy & Bani & - & - & - & 445 & 428 & $4.4 \pm 0.4$ & & 96 \\
\hline Atkins & P. Plata & 260 & 171 & $8.0 \pm 0.6$ & - & - & & 66 & \\
\hline
\end{tabular}

Legend: MSB; Mango Stem Bark; MBT: Mango Branch Tree.

The best extract yield (12.4\%) was obtained from Haden $\mathrm{SB}$, Bani farm, being significant higher than extracts of other mango by-products. BT extracts from the same variety had the lowest extraction yield, but it seems to have the highest content of polyphenols and MF, although it was non- significant statiscally. MF content in the polyphenol fraction ranged from $41,6 \%$ (BT Tommy Atkins) to $55.4 \%$ (SB Haden). Results of extraction procedures and chemical analysis of mango by-products extracts from both varieties are shown in Table 2.

Table 2. Chemical analysis of mango agricultural by-products extracts (stem bark and branch tree) from Haden and Tommy Atkins varieties, after Sohxlet extraction (70:30 methanol: deionized water).

\begin{tabular}{|c|c|c|c|c|c|c|}
\hline \multirow{2}{*}{ Variety/By-product } & \multicolumn{3}{|c|}{ Extraction } & \multirow{2}{*}{ Water (\%) } & \multirow{2}{*}{ PPC (g/100 g) } & \multirow{2}{*}{ MF (g/100 g) } \\
\hline & Initial (g) & Extract (g) & Yield (\%) & & & \\
\hline Haden/SB & 100 & 12.4 & $12.4 \pm 0.8^{\mathrm{a}}$ & $5.2 \pm 0.8$ & $15.8 \pm 1.5$ & $12.5 \pm 1.7$ \\
\hline Haden/BT & 100 & 8.4 & $8.4 \pm 0.7$ & $4.9 \pm 0.7$ & $16.2 \pm 1.2$ & $13.5 \pm 0.8$ \\
\hline T. Atkins/SB & 100 & 9.5 & $9.5 \pm 0.5$ & $4.7 \pm 0.8$ & $16.2 \pm 1.5$ & $13.3 \pm 2.0$ \\
\hline T. Atkins/BT & 100 & 9.7 & $9.7 \pm 0.6$ & $4.4 \pm 0.8$ & $13.9 \pm 0.5^{\mathrm{a}}$ & $9.4 \pm 1.2^{\mathrm{a}}$ \\
\hline
\end{tabular}

Legend: SB: Stem Bark; BT, Branch Tree; PPC, Polyphenol Content; MF, Mangiferin.

Letters mean significant difference $(\mathrm{p}>0.05)$.

\subsection{Polyphenols by HPLC-DAD}

Results of the HPLC-DAD analysis, Haden variety byproducts, as the best option for obtaining polyphenol-rich extracts, are shown in Table 3. Components were identified per retention times as compared to pure standards except for isomangiferin. Gallic acid (0.7-1.3\%), methyl gallate (1.6$1.8 \%)$, propyl gallate $(1.7 \%)$, catechin $(5.0-7.4 \%)$, epicatechin (4.4-6.3\%), MF (76.2-77.5\%), iso-MF (5.2-6.9\%), and quercetin $(0.8-1.9 \%)$ could be identified on extracts from both, $\mathrm{SB}$ and BT by-products. MF content ranged from 10.5 (BT) to 12.0 (SB) g/100 g d. w. Tommy Atkins MF content (BT) was comparatively lower than both by-products from Haden. MF extracted from both Haden extracts were identical qualitatively, in terms of proportion MF: isoMF.

The collection and storage of mango agricultural by-products following a SOP is crucial for extract standardization. Variables as land geographic site, soil type, parts to be collected (i.e. fruit, peel, kernel, SB or BT), and procedures for collection must be considered for the adequate elaboration of a SOP in order to obtain the best collection yield. Although the SB collection yields $(46 \%-66 \%)$ were lower than those from BT $(88 \%-96 \%)$, $\mathrm{PPC}$ and MF concentrations were significantly higher in the SB extracts. Nevertheless, these values were similar in BT extracts 
from the Haden variety (Table 2). Mango variety may affect chemical composition of by-products extracts as it has been demonstrated i.e. for its mineral content [17]. The high PPC and MF concentrations from the Haden mango extracts should be considered as evidences on the selection of this variety for future commercial exploitation of polyphenol-rich extracts from mango by-products. However, other mango varieties should be studied to determine options for the valorization of mango agricultural by-products for the production of polyphenol-rich extracts.

Table 3. High Performance Liquid Chromatography-Diode Array Detector analysis of mango branch tree and stem bark extracts from Haden variety (Mangifera indica L.).

\begin{tabular}{|c|c|c|c|c|c|c|c|}
\hline \multirow{2}{*}{ Component } & \multirow{2}{*}{ RT (min) } & \multicolumn{3}{|c|}{ BT } & \multicolumn{3}{|c|}{ SB } \\
\hline & & Peak area & $\%$ & $\mathrm{~g} / 100 \mathrm{~g}$ & Peak area & $\%$ & $\mathrm{~g} / 100 \mathrm{~g}$ \\
\hline Gallic acid & $4.5 \pm 0.1$ & 9365 & 1.2 & $0.2 \pm 0.1$ & 11572 & 1.3 & $0.2 \pm 0.1$ \\
\hline Methyl gallate & $7.2 \pm 0.1$ & 9368 & 1.2 & $0.2 \pm 0.1$ & 11548 & 1.3 & $0.2 \pm 0.1$ \\
\hline$(+)$-Catechin & $11.8 \pm 0.2$ & 28875 & 3.7 & $0.6 \pm 0.5$ & 88850 & 6.3 & $1.0 \pm 0.7$ \\
\hline (-)-Epicatechin & $13.5 \pm 0.3$ & 33551 & 4.3 & $0.7 \pm 0.4$ & 33755 & 3.8 & $0.6 \pm 0.6$ \\
\hline Mangiferin & $14.6 \pm 0.2$ & 647692 & 83.3 & $13.5 \pm 0.8$ & 702718 & 79.1 & $12.5 \pm 1.7$ \\
\hline Quercetin & $19.6 \pm 0.4$ & 9350 & 1.2 & $0.2 \pm 0.2$ & 11550 & 1.3 & $0.2 \pm 0.1$ \\
\hline Total & & & & $16.2 \pm 1.2$ & & & $15.8 \pm 1.5$ \\
\hline
\end{tabular}

Legend: SB: Stem Bark, BT: Branch Tree, RT: Retention Time; tr, traces.

Antioxidant properties of mango extracts, mainly from SB, have been extensively studied, both pre-clinical and clinical [15]. Phenolic antioxidants of the Haden mango SB have been studied being MF the main component of the polyphenol fraction (7 g/100 g d. w.) [14]. We found that MF content were 13.3, and $9.4 \mathrm{~g} / 100 \mathrm{~g}$ d.w for Tommy Atkins; 12.5 and 13.5 $\mathrm{g} / 100 \mathrm{~g}$ d.w. for Haden SB and BT by-products, respectively, which means that MF content in the polyphenolic extracts from these varieties cultivated in Dominican Republic were almost two times higher than that previous study with Cuban mangoes. Haden accounted for $79 \%$ and $83 \%$, and Tommy Atkins for $82 \%$ and $68 \%$ of the MF content in the PPC values for SB, and BT extracts, respectively. Probably, the lower latitude of Dominican Republic as compared to Cuba (higher sun radiation), and the difference on soil types (ferralytic in Cuba vs clay in Dominican Republic) might explain these results. A comparison of antioxidant activities of mango peel liqueurs, for the same varieties reported in the present work (Haden, and Tommy Atkins), concluded that Haden had the highest antioxidant activity, which was correlated to its higher PPC by Principal Component Analysis [19]. The chemopreventive effects of leaf extracts from Haden and Ataulfo mango varieties have been reported to be higher than Kent, Francis, and Tommy Atkins varieties on SW-480 colon carcinoma cells, and that effect was attributed to its antioxidant capacity, and the increase of apoptopic biomarkers [20]. Thus, the selection of the Haden variety as a source for obtaining polyphenol-rich extracts seems to be appropriated for further product development.

Extraction and purification of MF from mango byproducts extracts sometimes yield a mixture of xanthones being MF (2- $\beta$-D-glucopyranosyl-1,3,6,7-tetrahydroxy-9Hxanthen-9-one), and iso-MF (4- $\beta$-D-gluco-pyranosyl-1,3,6,7tetrahydroxy-9H-xanthen-9-one) the major components with an approximate ratio of 9:1 as determined in Brazilian mango seed and kernel [3]. The presence of iso-MF in purified MF has been reported also in several Chinese mango varieties and a report claims that iso-MF might be more active than MF as antiviral in herpes simplex [21, 22].

Valorization of agricultural by-products for both the obtainment of high value-added products, and the reduction of green house-gas emissions to the atmosphere has received considerable attention from the scientific and engineering community [23]. Concepts such as "biorefinery" and "circular economy" have emerged as a consequence, and many reports have been published in this field [24, 25]. Our results may be considered as a contribution to the approach to apply the concept of "circular economy" in mango plantations considering the use of BT, and SB for obtaining polyphenol-rich extracts from these green raw materials. Chemical characterization of polyphenols but also other significant components, which may contribute to the observed ethnomedical and in vitro, or in vivo biological effects, is a challenge that is always facing natural products researchers. Nevertheless, the main effort on mango-derived products has been focused on the potential of mango seeds and peels, as by-products of mango fruit industry, for their use as raw material for the production of polyphenolic-rich bioactive compounds [26].

A procedure using microwave irradiation and subsequent solvent extraction yield approximately $8 \mathrm{~g} / 100 \mathrm{~g} \mathrm{~d}$.w. of polyphenols in seed kernel, Keitt variety [27]. A solvent extraction procedure on dehydrated kernel powder and peel (Tommy Atkins variety) yield a PPC between 2 and $15 \mathrm{~g} / 100$ g d.w., respectively, which means that probably the highest PPC in mango by-products for obtaining polyphenol-rich extracts would be found in the seed kernel [7]. These previous reports did not determine the MF content in the polyphenol fraction. MF yield from mango leaves, Osteen variety (more than $1 \mathrm{~g} / 100 \mathrm{~g}$ d.w.) has been reported using supercritical fluids and sub-critical water $\left(100^{\circ} \mathrm{C}, 40\right.$ bar) [14]. However, MF content reported for leave extracts from mango Ataulfo variety was extremely low $(1.2 \mathrm{mg} / 100 \mathrm{~g})$, probably due to the use of acetone as the extracting solvent 
[28]. Similar results were obtained when a mixture of hexane: acetone was employed for polyphenols extraction from peel and seed kernel, Tommy Atkins variety [9].

Generally, the polyphenol concentration is higher in fruit biowastes than in fruit pulp [29]; several polyphenol-rich extracts from these sources have been increasingly marketed as grape seed extract from wine production waste hydrotyrosol from olive oil factories wastes, and resveratrol from pomegranate peel waste, just to mention few examples [30-32]. Mango SB extract has shown higher protective effects against oxidative stress than vitamins $\mathrm{C}$ and $\mathrm{E}$ [33]. Its antioxidant profile has been reviewed, and it has been assumed that its major component (MF) accounts for this biological effect [34]. Although MF has a poor solubility in water, it may be bioavailable in human plasma, and therefore it would be possible to use on cosmetic and pharmaceutical formulations, besides its benefits as antioxidant in nutraceutic supplements $[35,36]$. MF has shown to have five polymorphs, depending on the extraction conditions; and the amorphous crystalline form has the highest water-solubility in acid medium [37]. The potential benefits of MF for human health have been reviewed and it has the potential as an anti-inflammatory or immunomodulatory agent in several neurodegenerative diseases [38, 39].

\subsection{Polyphenols by HPLC-ESI-MS}

According to previous described results on polyphenolic composition, we decided to study more in depth the Haden mango SB extract, in order to complete the identification of other polyphenols, which may contribute to its observed biological effects. Figure 1 shows the chromatogram of HPLC-ESI-MS analysis of that extract. 52 peaks were recorded, from which $20(38 \%)$ could be identified by comparison to the mass spectra of pure standard compounds when available, or by comparison of their mass spectra and fragmentation patterns to published mass spectral data.

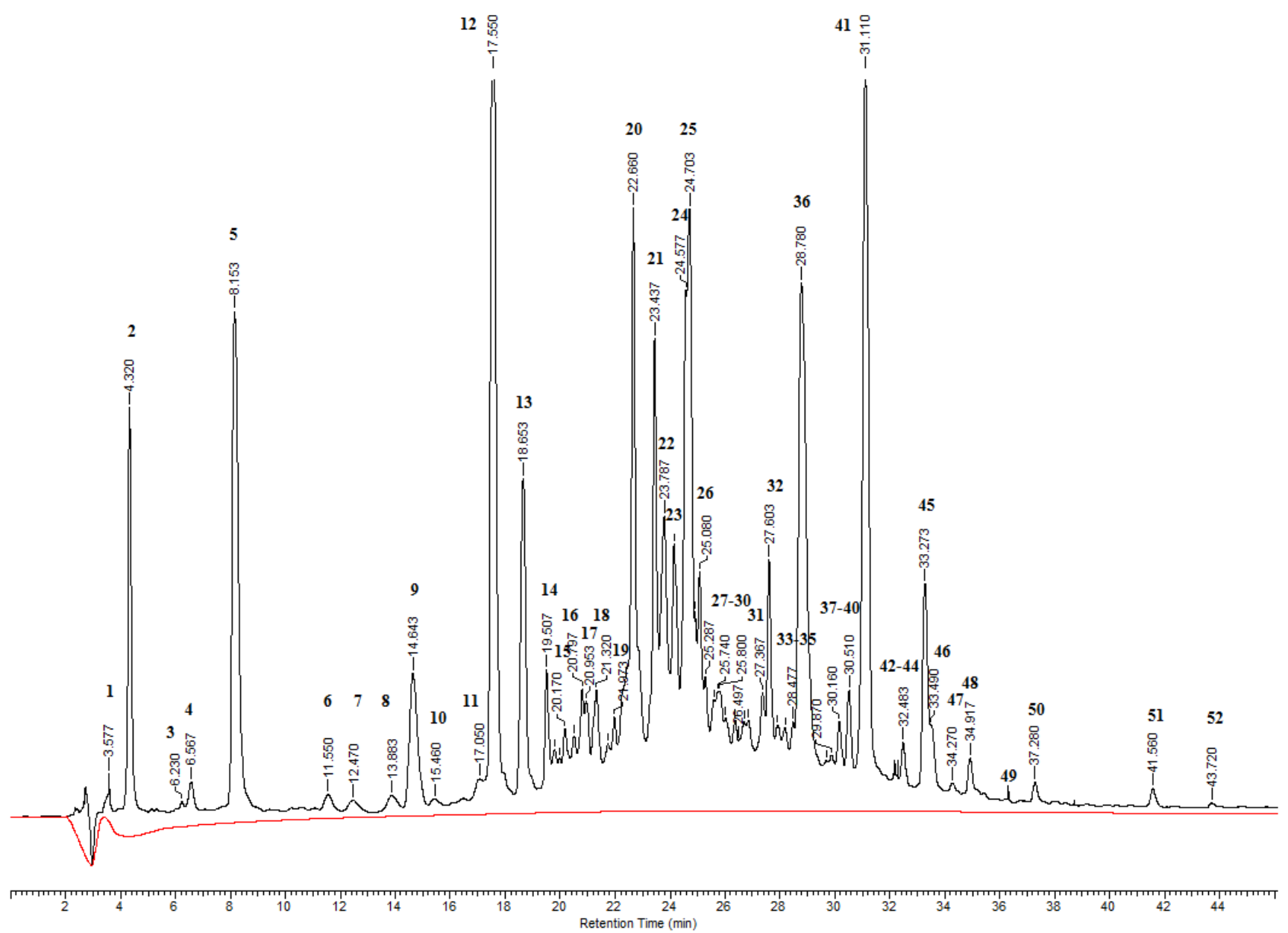

Figure 1. High Performance Liquid Chromatography-Electrospray Ionization-Negative-ion-Mass Spectrometry (HPLC-ESI-MS) chromatogram of mango stem bark extract butanolic extract, Haden variety. Identified components: 1. Monogalloyl glucose, 2. Gallic acid, 3. Methyl gallate, 4. Glucomangiferin, 5. 3,4-Dihydroxybenzoic acid, 6. Maclurin 3-(2-galloyl)- $\beta$-D-glucoside, 7. Iriflophenone 3-C- $\beta$-D-glucoside, 8. Propyl gallate, 9. (+)-Catechin, 10. Unknown, 11. (-) Epicatechin, 12. Mangiferin, 13. Isomangiferin, 14. Homomangiferin, 15. Benzophenone derivative, 16. 6'-O-galloyl-2'-benzoyl-mangiferin, 17. 6'-Ogalloyl-mangiferin, 18. 6'-O-galloyl-mangiferin isomer, 19. Mangiferin isomer, 20. 6'-O-galloyl -isomangiferin, 21. X'-O-galloyl-mangiferin, 22. Flavonone derivative, 23. 6'-O-galloyl-mangiferin isomer, 24. X'-O-galloyl-mangiferin isomer, 25. X'-O-galloyl-mangiferin isomer, 26-35. Unknown, 36. 3C-6'-O-p- hidroxybenzoyl mangiferin, 37-40. Unknown, 41. Noratyriol, 42-45. Unknown, 46. Quercetin, 47-52. Unknown.. Experimental data are shown in Table 4 . 
Peak 1 ( $\mathrm{RT}=3.57 \mathrm{~min})$ had a UV spectrum similar to gallic acid, and $[\mathrm{M}-\mathrm{H}]^{-}$ion=331 m/z. Fragmentation patterns (MS1 and MS2) showed typical fragments of glucose: $\mathrm{m} / \mathrm{z}=\left[\mathrm{M}-\mathrm{H}^{-}-\right.$ 120], [M-H-90], and [M-H-60], and the $[\mathrm{M}-\mathrm{H}]^{-}$ion of gallic acid $(\mathrm{m} / \mathrm{z}=169)$. Peak compound was identified unambiguously as monogalloyl glucose $(\mathrm{MW}=332.26)$. Peak $2(\mathrm{RT}=4.32 \mathrm{~min})$ was identified as gallic acid by comparison with a pure standard $(\mathrm{MW}=170.10)$. Peak $3(\mathrm{RT}=6.23 \mathrm{~min})$ was identified as methyl gallate by comparison with a pure standard $(\mathrm{MW}=184.03)$. Peak $4(\mathrm{RT}=6.56 \mathrm{~min})$ had a UV spectrum similar to MF, with four absorption peaks (240, 260, 320, and $365 \mathrm{~nm}$ ), and $[\mathrm{M}-\mathrm{H}]^{-}$ion=583 $\mathrm{m} / \mathrm{z}$. Fragmentation patterns (MS1 and MS2) showed typical fragments of glucose: $\mathrm{m} / \mathrm{z}=\left[\mathrm{M}-\mathrm{H}^{-}-120\right]$, and $\left[\mathrm{M}-\mathrm{H}^{-}-90\right]$. Other fragments $(\mathrm{m} / \mathrm{z}=403$, [M-H-90-90]; and $\mathrm{m} / \mathrm{z}=373$, [M$\left.\mathrm{H}^{-}-120-120\right]$ ) evidenced the loss of a second glucose moiety, which lead to identify this compound as glucomangiferin $(\mathrm{MW}=584.48)$. Peak 5 (RT=8.15 min) was identified as 3,4dihydroxybenzoic acid by comparison with a pure standard $(\mathrm{MW}=154.12)$. Peak $6 \quad(\mathrm{RT}=11.55 \mathrm{~min})$ showed three absorption maxima (230, 260, and $295 \mathrm{~nm})$ typical of benzophenone, and $[\mathrm{M}-\mathrm{H}]^{-}$ion $=575 \mathrm{~m} / \mathrm{z}$. Fragmentation patterns (MS1 and MS2) showed fragments at $\mathrm{m} / \mathrm{z}=423[\mathrm{M}$ $\left.\mathrm{H}^{-}-152\right]$, and $405\left[\mathrm{M}-\mathrm{H}^{-}-170\right]$, due to the loss of a galloyl radical; $\mathrm{m} / \mathrm{z}=313\left[\mathrm{M}-\mathrm{H}^{-}-152-110\right]$, and $303\left[{\left.\mathrm{M}-\mathrm{H}^{-}-152-120\right]}^{-15}\right.$ due to the loss of a glucose moiety; and $\mathrm{m} / \mathrm{z}=261$, which is the molecular ion of the benzophenone nucleus. The fragmentation pattern lead to identify this peak compound unambiguously as maclurin 3-(2-galloyl)- $\beta$-D-glucoside (MW: 576.11). Peak $7 \quad(\mathrm{RT}=12.47 \mathrm{~min})$ showed two absorption maxima (235, and $290 \mathrm{~nm}$ ), and [M-H] $]^{-}$ion=407 $\mathrm{m} / \mathrm{z}$. Fragmentation patterns (MS1 and MS2) showed fragments at $\mathrm{m} / \mathrm{z}=317,\left[\mathrm{M}-\mathrm{H}^{-}-90\right]$, and 287, [M-H'-120], typical fragments for the loss of a glucose moiety, and $\mathrm{m} / \mathrm{z}=245$, which is another molecular ion of the benzophenone nucleus. Peak compound was unambiguously identified as iriflophenone 3-C- $3-\mathrm{D}$-glucoside ( $\mathrm{MW}=408.07$ ). Peak $8(\mathrm{RT}=13.88$ was identified as propyl gallate by comparison with a pure standard $(\mathrm{MW}=212.20)$. Peak 9 $(\mathrm{RT}=14.64 \mathrm{~min})$ was identified as $(+)$-catechin by comparison with a pure standard $(\mathrm{MW}=290.27)$. Peak 10 $(\mathrm{RT}=15.46 \mathrm{~min})$ showed two absorption maxima at 230 , and $275 \mathrm{~nm}$, and a molecular ion $[\mathrm{M}-\mathrm{H}]^{-}=565 \mathrm{~m} / \mathrm{z}$. Fragmentation pattern (MS1 and MS2) showed the loss of a glucose moiety, but it could not be identified. Peak $11(\mathrm{RT}=17.05)$ was identified as (-)-epicatechin by comparison with a pure standard $(\mathrm{MW}=290.27)$. Peak $12 \quad(\mathrm{RT}=17.55 \mathrm{~min})$ was identified as MF by comparison with a pure standard (MW=422.34). Peak 13 (RT=18.65 min) showed a UV spectrum with two maxima at 230, and $290 \mathrm{~nm}$, and [M-H] ion $=421 \mathrm{~m} / \mathrm{z}$, which could be identified as iso-MF (4- $\beta-\mathrm{C}$ glucopyranosyl-1,3,6,7-tetrahydroxy-9H-xanthen-9-one) by comparison with the MF standard impurity. Peak 14 ( $R T=19.50$ min) showed a UV spectrum similar to MF with four absorption maxima and $[\mathrm{M}-\mathrm{H}]^{-}$ion $=435 \mathrm{~m} / \mathrm{z}$, and the typical fragmentation pattern as MF. It was unambiguously identified as homomangiferin, 3-O-methyl-2 $\beta$-Dglucopyranosyl-1,3,6,7-tetrahydroxy-9H-xanthen-9-one $(\mathrm{MW}=436.40)$. Peak $15(\mathrm{RT}=20.17)$ showed two UV maxima at 235 , and $265 \mathrm{~nm}$, and $[\mathrm{M}-\mathrm{H}]^{-}$ion= $261 \mathrm{~m} / \mathrm{z}$, corresponding to a benzophenone derivative. Peak 16 ( $\mathrm{RT}=20.79 \mathrm{~min})$ showed a similar UV spectrum as MF, and $[\mathrm{M}-\mathrm{H}]^{-}$ion=693 $\mathrm{m} / \mathrm{z}$. Fragmentation patterns (MS1 and MS2) showed fragments at $\mathrm{m} / \mathrm{z}=573,\left[\mathrm{M}^{-} \mathrm{H}^{-}-120\right], 421,\left[\mathrm{M}^{-} \mathrm{H}^{-}-120-152\right]$, and 403, [M-H-120-170], due to the loss of benzoyl, and galloyl radicals, and a gallic acid moiety, respectively. MS2 on $\left[\mathrm{M}-\mathrm{H}^{-}\right]$ion showed a high peak at $\mathrm{m} / \mathrm{z}=\left[\mathrm{M}-\mathrm{H}^{-}-272\right]$, typical of the MF fragmentation pattern. It was unambiguously identified as 6'-O-galloyl-2'-benzoylmangiferin $(\mathrm{MW}=694.09)$. Peak $17(\mathrm{RT}=20.95 \mathrm{~min})$ showed a similar UV spectrum as $\mathrm{MF}$, and $[\mathrm{M}-\mathrm{H}]^{-}$ion $=573 \mathrm{~m} / \mathrm{z}$. Fragmentation patterns (MS1 and MS2) showed fragments at $\mathrm{m} / \mathrm{z}=421$ [M-H $\left.^{-}-152\right]$, and 403 [M-H'-120-18], due to the loss of a galloyl radical, and a water moiety, respectively. MS2 on $\left[\mathrm{M}-\mathrm{H}^{-}\right]$ion showed a high peak at $\mathrm{m} / \mathrm{z}=\left[\mathrm{M}-\mathrm{H}^{-}-152\right]$, typical of the MF fragmentation pattern. It was unambiguously identified as 6'-O-galloyl-mangiferin ( $\mathrm{MW}=574.09)$. Peak 18 $(\mathrm{RT}=21.32 \mathrm{~min}$ ) showed a UV and mass spectra similar to 6'O-galloyl-mangiferin as previously described. Peak resolution was enough to identify it as an isomer of 6'-Ogalloyl-mangiferin, but it could not be specifically identified. Peak $19(\mathrm{RT}=21.97)$ showed a similar UV and mass spectra as MF, and it was assumed to be a MF isomer, but we could not identify the isomer type. Peak 20 (RT=22.66 min) showed a similar UV spectrum as MF, and $[\mathrm{M}-\mathrm{H}]^{-}$ion $=573$ $\mathrm{m} / \mathrm{z}$. Fragmentation patterns (MS1 and MS2) showed fragments at $\mathrm{m} / \mathrm{z}=421,\left[\mathrm{M}-\mathrm{H}^{-}-152\right], 331,\left[\mathrm{M}^{-} \mathrm{H}^{-}-90\right]$, and 301, [M-H-120], due to the loss of a galloyl radical, and a glucose moiety, respectively. MS2 on $\left[\mathrm{M}-\mathrm{H}^{-}\right]$ion showed a high peak at $\mathrm{m} / \mathrm{z}=\left[\mathrm{M}-\mathrm{H}^{-}-152\right]$, typical of the MF fragmentation pattern. It was unambiguously identified as 6'-O-galloylisomangiferin $(\mathrm{MW}=574.09)$. Peak $21 \quad(\mathrm{RT}=23.43 \mathrm{~min})$ showed a similar UV spectrum as MF, and $[\mathrm{M}-\mathrm{H}]^{-}$ion=573 $\mathrm{m} / \mathrm{z}$. Fragmentation patterns (MS1and MS2) showed fragments at $\mathrm{m} / \mathrm{z}=421,\left[\mathrm{M}-\mathrm{H}^{-}-152\right]$, and $403,\left[\mathrm{M}^{-} \mathrm{H}^{-}-120-18\right]$, due to the loss of a galloyl radical, and a water moiety, respectively. MS2 on $\left[\mathrm{M}-\mathrm{H}^{-}\right]$ion showed a high peak at $\mathrm{m} / \mathrm{z}=\left[\mathrm{M}-\mathrm{H}^{-}-152\right]$, typical of the MF fragmentation pattern. It was unambiguously identified as $\mathrm{X}^{\prime}$-O-galloyl-mangiferin $(\mathrm{MW}=574.09)$. Peak $22 \quad(\mathrm{RT}=23.78 \mathrm{~min})$ had the fragmentation pattern of a flavanone derivative, but it could not be identified. Peak 23 (RT=24.11 min) had UV and mass spectra identical to peak 16 , which suggested the presence of a position isomer of 6'-O-galloyl-mangiferin ( $\mathrm{MW}=574.09$ ). Peaks $24(\mathrm{RT}=24.57 \mathrm{~min})$, and $25(\mathrm{RT}=24.70 \mathrm{~min})$ showed UV and mass spectra identical to peak 21, which suggested that both compounds were position isomers of X'-O-galloylmangiferin $(\mathrm{MW}=574.09)$. Peaks 24 to 35 ( $\mathrm{RT}=25.08$ to 28.47) could not be identified due to their low concentrations. Peak 36 (RT=28.78 min) showed three absorption maxima at 245, 270, and $305 \mathrm{~nm}$, and a molecular ion $[\mathrm{M}-\mathrm{H}]^{-}=541 \mathrm{~m} / \mathrm{z}$. Fragmentation patterns (MS1 and MS2) 
showed a fragment at $\mathrm{m} / \mathrm{z}=403,\left[\mathrm{M}-\mathrm{H}^{-}-138\right]$, due to the loss of a p-hydroxibenzoic acid moiety. MS2 on $\left[\mathrm{M}-\mathrm{H}^{-}\right]$ion showed a high peak at $\mathrm{m} / \mathrm{z}=\left[\mathrm{M}-\mathrm{H}^{-}-138\right]$, and typical fragments of the MF pattern $(\mathrm{m} / \mathrm{z}=331,301$, and 259$)$. It was unambiguously identified as 3-C-6'-O-p- hidroxybenzoylmangiferin ( $\mathrm{MW}=542.45)$. Peaks 37 to $40(\mathrm{RT}=29.21$ to 30.51) could not be identified due to their low concentrations. Peak $41(\mathrm{RT}=31.11 \mathrm{~min})$ showed a similar $\mathrm{UV}$ spectrum as $\mathrm{MF}$, and $[\mathrm{M}-\mathrm{H}]^{-}$ion $=259 \mathrm{~m} / \mathrm{z}$. It was unambiguously identified as noratyriol $(\mathrm{MW}=260.19)$, a known MF metabolite from C-C bond rupture of the glucose moiety. Peaks 42 to 44 (RT=31.98 to 32.48) could not be identified due to their low concentrations. Peak 45 $(\mathrm{RT}=33.27)$ showed two UV maxima $(235$, and $290 \mathrm{~nm})$ and $[\mathrm{M}-\mathrm{H}]^{-}$ion $=519 \mathrm{~m} / \mathrm{z}$, corresponding to a benzophenone derivative. Peak 46 ( $\mathrm{RT}=33.49 \mathrm{~min})$ was identified as quercetin by comparison to a pure standard ( $\mathrm{MW}=302.19)$. Peaks 47 to 52 ( $R T=34.27$ to 43.72$)$ could not be identified due to their low concentrations.

Summarizing, our results led to the unambiguous identification of 20 components (peaks 1-9, 11-14, 16, 17, 20, $21,36,41$, and 46), and the tentative identification of $5 \mathrm{MF}$ or iso-MF derivative isomers (peaks 18, 19, and 23-25), 2 benzophenone derivatives (peaks 15, and 45), and 1 flavanone derivative (peak 22) from the Haden mango SB butanolic extract. Table 4 shows the results of the unambigous identification of extract components, and the structure estimation of other components not fully identified, in the butanolic extract of the Haden mango SB by HPLC-ESI-MS. Figure 2 shows the structures of the identified components.

Several gallotannins and benzophenone derivatives have been identified in mango peels, pulp, and kernel (Tommy Atkins) by HPLC/ESI/MS as galloylated maclaurin and iriflophenone glucosides [40]. Gallates, gallotannins, flavonoids, ellagic acid, xanthones, benzophenones, and maclaurin derivatives have been identified in microwaveassisted extracts from peel and seeds of 3 mango varieties (Keith, Sensation, and Gomera) cultivated in Spain [8]. The identification of 32 gallates and gallotannins, 7 hydroxybenzophenone (maclurin and iriflophenone) derivatives, 6 xanthonoids (including isomangiferin and MF derivatives); 11 phenolic acids, and 8 flavonoids (rhamnetin and quercetin derivatives) was performed by UPLC-ESI-MS in peel and pulp of Keith and Tommy Atkins mango varieties in Costa Rica [40]. Our results are similar to those previous results in terms of qualitative polyphenols composition, but this is the first report from the Haden mango stem bark extract. Tommy Atkins, Keith, and other mango varieties have been the most studied in terms of polyphenolics composition; however, the Haden mango seems to be more attractive in terms of higher PPC than other mango varieties.

Table 4. High Performance Liquid Chromatography-Electrospray Ionization-Negative-ion-Mass Spectrometry-Diode Array Detector analysis of butanol extract from the mango stem bark, Haden variety (Mangifera indica L.). Chromatogram is shown in Figure 1.

\begin{tabular}{|c|c|c|c|c|c|c|c|c|c|}
\hline \multirow{2}{*}{$\begin{array}{l}\text { Peak } \\
1\end{array}$} & \multirow{2}{*}{$\begin{array}{l}\text { RT } \\
(\mathrm{min})\end{array}$} & \multirow{2}{*}{$\begin{array}{l}\text { Identitiy } \\
\text { Monogalloyl glucose }\end{array}$} & \multicolumn{4}{|c|}{ HPLC-DAD $\lambda_{\max }(\mathbf{n m})$} & \multirow{2}{*}{$\begin{array}{l}(\mathbf{M}-\mathbf{H})^{-} \\
(\mathbf{m} / \mathbf{z})\end{array}$} & \multirow{2}{*}{$\begin{array}{l}\text { HPLC-ESI-(-)MS }^{\mathbf{n}}(\mathbf{m} / \mathbf{z}) \\
169^{2}, 211^{2}, 241^{2}, 271^{2}\end{array}$} & \multirow{2}{*}{$\begin{array}{l}\text { Calculated } \\
\text { mass }(\mathbf{m} / \mathbf{z})\end{array}$} \\
\hline & & & 230 & 265 & & & & & \\
\hline 2 & 4.32 & Gallic acid & 230 & 270 & & & 169 & $125^{2}, 169^{1}$ & 170.45 \\
\hline 3 & 6.23 & Methyl gallate & 230 & 265 & & & 183 & $124^{2}, 153^{1}, 168^{2}$ & 184.03 \\
\hline 4 & 6.56 & Glucomangiferin & 240 & 260 & 320 & 365 & 583 & $301^{2}, 343^{2}, 373^{2}, 403^{2}, 423^{1}, 445^{2}, 463^{2}, 475^{2}, 493^{2}$ & 584.48 \\
\hline 5 & 8.15 & 3,4-Dihydroxybenzoic acid & 230 & 260 & 295 & & 153 & $109^{2}$ & 154.12 \\
\hline 6 & 11.55 & Maclurin 3-(2-galloyl)-ß3-D-glucoside & 230 & 285 & & & 575 & $113^{1}, 159^{1}, 261^{2}, 303^{2}, 313^{2}, 407^{1}, 423^{2}, 439^{2}$ & 576.11 \\
\hline 7 & 12.47 & Iriflophenone 3-C- $ß-\mathrm{D}$-glucoside & 235 & 290 & & & 407 & $113^{1}, 159^{1}, 207^{1}, 287^{2}, 317^{2}, 329^{2}$ & 408.07 \\
\hline 8 & 13.88 & Propyl gallate & 230 & 265 & & & 211 & $124^{2}, 168^{2}, 169^{1}$ & 212.20 \\
\hline 9 & 14.64 & $(+)$-Catechin & 235 & 280 & 315 & 365 & 289 & $137^{1}, 159^{1}, 179^{2}, 205^{2}, 245^{1}$ & 290.27 \\
\hline 11 & 17.05 & $(+)$-Epicatechin & 235 & 280 & 315 & 365 & 289 & $137^{1}, 159^{1}, 179^{2}, 205^{2}, 245^{2}$ & 290.27 \\
\hline 12 & 17.55 & Mangiferin & 240 & 255 & 320 & 365 & 421 & $259^{2}, 272^{1}, 301^{2}, 331^{2}, 403^{2}$ & 422.34 \\
\hline 13 & 18.65 & Isomangiferin & 240 & 255 & 320 & 365 & 421 & $259^{2}, 272^{1}, 301^{2}, 331^{2}, 403^{2}$ & 422.34 \\
\hline 14 & 19.50 & Homomangiferin & 240 & 260 & 320 & 360 & 435 & $272^{2}, 287^{2}, 315^{2}, 345^{2}$ & 436.33 \\
\hline 15 & 20.17 & Benzophenone derivative & 235 & 295 & & & 261 & $106^{2}, 151^{2}, 196^{2}, 218^{2}$ & Unknown \\
\hline 16 & 20.79 & 6'-O-galloyl -2'-benzoyl-mangiferin & 235 & 260 & 320 & 365 & 693 & $301^{2}, 331^{2}, 403^{2}, 405^{1}, 421^{2}, 573^{2}$ & 694.24 \\
\hline 17 & 20.95 & 6'-O-galloyl -mangiferin & 240 & 260 & 320 & 365 & 573 & $259^{2}, 283^{2}, 301^{2}, 331^{2}, 403^{2}, 421^{2}, 435^{1}$ & 574.09 \\
\hline 18 & 21.32 & 6'-O-galloyl-mangiferin isomer & 235 & 260 & 320 & 360 & 573 & $259^{2}, 283^{2}, 301^{2}, 331^{2}, 389^{1}, 403^{2}, 421^{2}, 435^{1}$ & 574.09 \\
\hline 19 & 21.97 & Mangiferin isomer & 235 & 260 & 320 & 365 & 421 & $259^{2}, 271^{1}, 301^{2}, 331^{2}, 403^{1}$ & 422.34 \\
\hline 20 & 22.66 & 6'-O-galloyl-isomangiferin & 235 & 260 & 320 & & 573 & $259^{2}, 301^{2}, 331^{2}, 421^{1}$ & 574.09 \\
\hline 21 & 23.43 & $X^{\prime}$-O-galloyl-mangiferin & 240 & 260 & 320 & 360 & 573 & $211^{2}, 271^{2}, 301^{2}, 331^{2}, 421^{2}, 453^{2}$ & 574.09 \\
\hline 22 & 23.78 & Flavonone derivative & 240 & 255 & 320 & 360 & 403 & $271^{1}, 301^{2}, 331^{2}$ & Unknown \\
\hline 23 & 24.11 & 6'-O-galloyl-mangiferin isomer & 235 & 260 & 320 & 360 & 573 & $211^{2}, 241^{2}, 271^{2}, 301^{2}, 331^{2}, 403^{2}, 421^{2}, 453^{2}$ & 574.09 \\
\hline 24 & 24.57 & $\mathrm{X}^{\prime}$-O-galloyl-mangiferin isomer & 240 & 255 & 320 & 360 & 573 & $259^{2}, 271^{2}, 301^{2}, 311^{2}, 403^{2}, 421^{1}, 473^{2}$ & 574.09 \\
\hline 25 & 24.70 & $\mathrm{X}^{\prime}$-O-galloyl-mangiferin isomer & 240 & 255 & 320 & 360 & 573 & $259^{2}, 271^{2}, 301^{2}, 311^{2}, 403^{2}, 473^{1}$ & 574.09 \\
\hline 36 & 28.78 & 3-C-6'-O-p- hidroxybenzoylmangiferin & 240 & 270 & 310 & & 541 & $175^{1}, 301^{2}, 331^{2}, 403^{2}, 421^{2}$ & 542.05 \\
\hline 41 & 31.11 & Noratyriol & 235 & 255 & 315 & 360 & 259 & $187^{2}, 216^{2}, 231^{2}$ & 260.19 \\
\hline 45 & 33.27 & Benzophenone derivative & 235 & 290 & & & 519 & $165^{2}, 259^{1}, 327^{1}$ & Unknown \\
\hline 46 & 33.49 & Quercetin & 235 & 255 & 370 & & 301 & $113^{1}, 151^{2}, 179^{2}, 257^{2}, 273^{2}$ & 302.24 \\
\hline
\end{tabular}


1. Monogalloyl glucose<smiles>O=C(OC1OCC(O)C(O)C(O)C1O)c1cc(O)c(O)c(O)c1</smiles>

4. Glucomangiferin

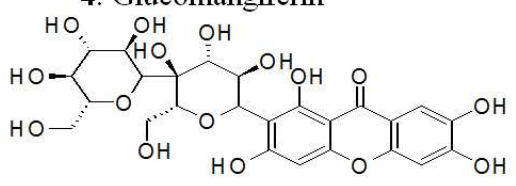

7. Iriflophenone 3-C-B-D-glucoside

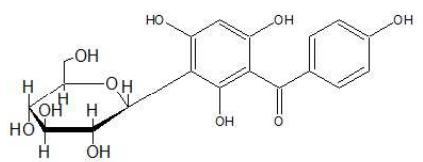

11. (-) Epicatechin<smiles>Oc1cc(O)c2c(c1)O[C@H](c1ccc(O)c(O)c1)C(O)C2</smiles>

14. Homomangiferin<smiles>COc1cc2oc3cc(O)c(O)cc3c(=O)c2c(O)c1C1O[C@H](CO)[C@@H](O)C(O)C1O</smiles>

20. 6'-O-galloyl -isomangiferin

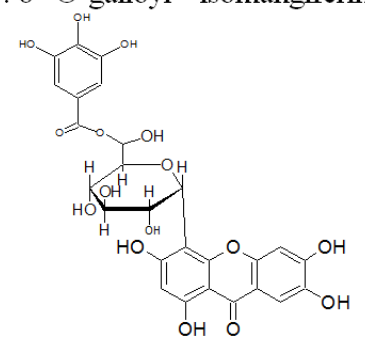

41. Noratyriol<smiles>O=c1c2cc(O)c(O)cc2oc2cc(O)cc(O)c12</smiles>

2. Gallic acid<smiles>O=C(O)c1cc(O)c(O)c(O)c1</smiles>

5. 3,4-Dihydroxybenzoic acid<smiles>O=C(O)c1ccc(O)c(O)c1</smiles>

8. Propyl gallate

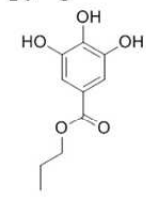

12. Mangiferin

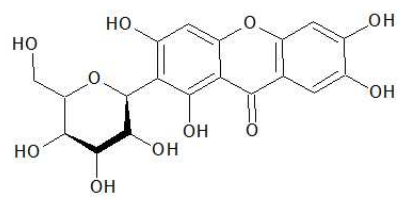

16. 6'-O-galloyl -2'-benzoylmangiferin

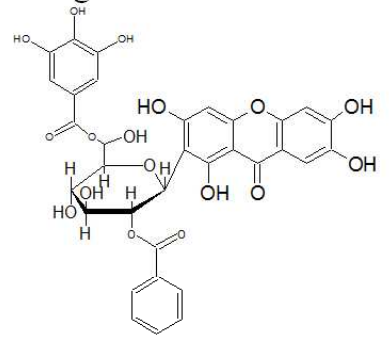

21. X'-O-galloyl -mangiferin

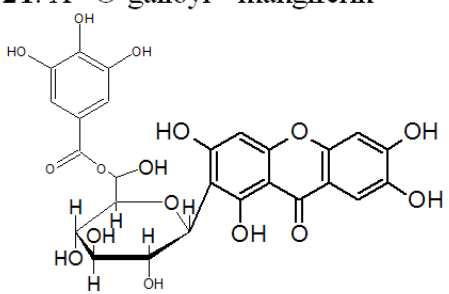

3. Methyl gallate<smiles>COC(O)C1CC(O)C(O)C(O)C1</smiles>

6. Maclurin 3-(2-galloyl)-ß-D-glucoside

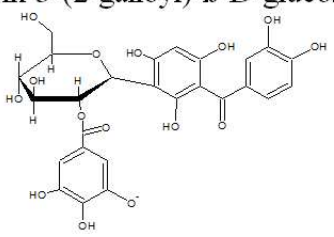

9. (+)-Catechin<smiles>Oc1cc(O)c2c(c1)O[C@H](c1ccc(O)c(O)c1)C(O)C2</smiles>

13. Isomangiferin

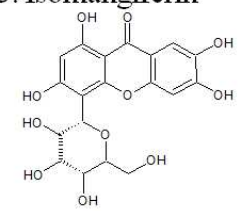

17. 6'-O-galloyl -mangiferin

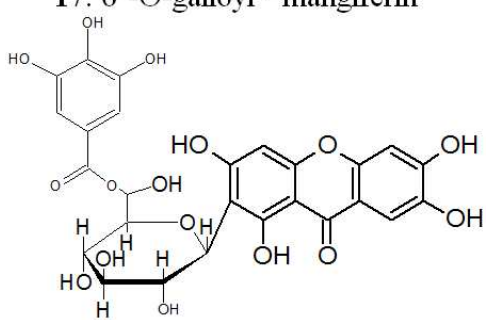

36.3-C-6'-O-p-hidroxybenzoyl mangiferin

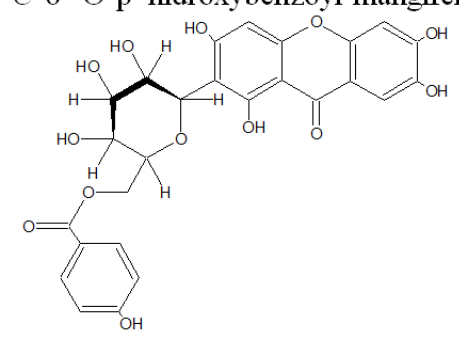

46. Quercetin<smiles></smiles>

Figure 2. Chemical structures of identified components in the Haden mango stem bark butanolic extract by High Performance Liquid ChromatographyElectrospray Ionization-Negative-ion-Mass Spectrometry (HPLC-ESI-MS). Structures were numbered according to peak numbers in the chromatogram (Figure 1).

The presence of a large diversity of xanthones, flavonoids, gallic acid and its derivatives, gallotannins, together with a large amount of terpenoids and steroids in mango fruit, peel, leaves, seeds, and stem bark is a complex matter for any researcher in the attempts to correlate chemical composition to the biological activities. It is commonly accepted that the contribution of single components to biological effects of mango extracts depends on variety, cultivation soil, climate 
conditions, and part of the plant used as green raw material. Therefore, our results should be considered as a report from a typical variety (Haden), in clay soils on tropical conditions, using SB or BT as agricultural by-products sources from Dominican mango plantations, as the best option for the production of polyphenol-rich extracts to be used as bioactive ingredients in nutraceutic, cosmeceutic and/or pharmaceutic formulations. Fourteen MF derivatives (peaks 4, 12 to 14, 16 to 21,23 to 25 , and 36 ) could be identified in the butanolic extract of the Haden mango SB extract in the present work, which led to the question if MF alone or the pool of MF derivatives are the responsible of the extract's biological effects, which needs to be investigated in the future. HPLCESI-MS analysis of the Haden mango SB extract showed the presence of many polyphenolic components, not previously reported, which may correlate to the antioxidant, antiinflammatory, and/or analgesic effects of this extract mostly through a synergic effect of its components. Significantly, the content of $(+)$-catechin in the SB extract was almost twice as compared to the BT extract (Table 2), which has to be considered in future studies about the contribution of this polyphenol to the extract biological effects. Further studies about polyphenol composition of other mango varieties in different locations would add a more comprehensive approach to this topic.

\section{Conclusions}

The potential exploitation of mango agricultural byproducts from the Haden variety would be the best option for obtaining polyphenol-rich extracts from these green raw materials to be used as bioactive ingredients in nutraceutical, cosmeceutical, and/or pharmaceutical formulations. HPLCESI-MS analysis of the Haden mango SB extract showed the presence of many polyphenolic components, not previously reported, which may correlate to the antioxidant, antiinflammatory, and/or analgesic effects of this extract mostly through a synergistic effect of its components. The presence of 14 MF-related derivatives led to the question if MF alone or the combination of MF derivatives is the responsible of the extract's biological effects, which needs to be investigated in the future.

\section{Abbreviations}

\author{
BT: Mango Branch Tree \\ DAD: Diode Array Detector \\ DMSO: Dimethylsulphoxide \\ ESI: Electrospray Ionization \\ HPLC: High Pressure Liquid Chromatography \\ MF: Mangiferin \\ MS: Mass Spectrometry \\ PPC: Polyphenol Content \\ RT: Retention Time \\ SB: Mango Stem Bark \\ SOP: Standardized Operational Procedure
}

\section{Supplementary Information}

File with chromatographic, UV, and MS data supporting compounds identification.

\section{Conflicts of Interest}

The authors declare that they have no competing interests.

\section{Acknowledgements}

The financial support from the National Development Fund of Science and Technology (FONDOCYT), Ministry of Higher Education, Science and Technology (MESCyT), and the National Evangelic University (UNEV), Dominican Republic, through Project 2015-2A3-062. To Dr. John Caccavale for English grammar revision.

\section{References}

[1] FAO Statistical Database. Agriculture. Food and Cultural Organization, Production Yearbook Food and Agricultural Organization of the United Nations. Rome, Italy. http://www.faostat/en/\#data/QC. (Accessed June 25th, 2020).

[2] Jahurul, M. H. A.; Zaidul, I. S. M.; Ghafoor, K.; Al-Juhaimi, F. Y.; Nyam, K. L.; Norulaini, N. A. N.; Sahena, F.; Omar, A. M. Mango (Mangifera indica L.) by-products and their valuable components: A review. Food Chem. 2015, 183, 173180. doi.org/10.1016/j.foodchem. 2015.03.046.

[3] Ribeiro, S. M. R.; Barbosa, L. C. A.; Queiroz, J. H.; Knödler, M.; Schieber, A. Phenolic compounds and antioxidant capacity of Brazilian mango (Mangifera indica L.) varieties. Food Chem., 2008, $110 \quad$ (3), 620-626. doi.org/10.1016/j.foodchem.2008.02.067.

[4] Li, L.; Wang, S.; Chen, J.; Xie, J.; Wu, H.; Zhan, R.; Li, W. Major antioxidants and in vitro antioxidant capacity of eleven mango (Mangifera indica L.) cultivars. Int. J. Food Prop., 2014, 17 (8), 1872-1887.

doi.org/10.1080/10942912.2012.687798.

[5] Larrauri, J. A.; Rupérez, P.; Borroto, B.; Saura-Calixto, F. Mango peels as a new tropical fibre: preparation and characterization. LWT-Food Sci. Technol., 1996, 29 (8), 729733. doi.org/10.1006/fstl.1996.0113.

[6] Umamahesh, K.; Sivudu, S. N.; Reddy, O. V. S. Evaluation of antioxidant activity, total phenolics and total flavonoids in peels of five cultivars of mango (Mangifera indica) fruit. J. Med. Plants Stud., 2016, 4 (2), 200-203. ISSN 2320-3862.

[7] Sogi, D. S.; Siddiq, M.; Greiby, I.; Dolan, K. D. Total phenolics, antioxidant activity, and functional properties of 'Tommy Atkins' mango peel and kernel as affected by drying methods. Food Chem., 2013, 141 (3), 2649-2655. doi.org/10.1016/j.foodchem.2013.05.053.

[8] Dorta, E.; González, M.; Lobo, M. G.; Sánchez-Moreno, C.; de Ancos, B. Screening of phenolic compounds in by-product extracts from mangoes (Mangifera indica L.) by HPLC-ESIQTOF-MS and multivariate analysis for use as a food ingredient. Food Res. Int., 2014, 57: 51-60. doi.org/10.1016/j.foodres.2014.01.012. 
[9] Ruales, J.; Baenas, N.; Moreno, D. A.; Stinco, C. M.; Meléndez-Martínez, A. J.; García-Ruiz, A. Biological active ecuadorian mango 'Tommy Atkins' ingredients-An opportunity to reduce agrowaste. Nutrients, 2018, 10 (9), 1138. doi: 10.3390/nu10091138.

[10] Stohs, S. J.; Swaroop, A.; Moriyama, H.; Bagchi, M.; Ahmad, T.; Bagchi, D. A review on antioxidant, anti-inflammatory and gastroprotective abilities of mango (Mangifera indica) leaf extract and mangiferin. J. Nutr. Health Sci., 2018, 5, 303. ISSN: 2393-9060.

[11] Fernández-Ponce, M. T.; Casas, L.; Mantell, C.; de la Ossa, E. $\mathrm{M}$. Use of high pressure techniques to produce Mangifera indica $\mathrm{L}$. leaf extracts enriched in potent antioxidant phenolic compounds. Innov. Food Sci. Emerg. Technol., 2015, 29, 94106. doi.org/10.1016/j.ifset. 2015.04.006.

[12] Zou, T. B.; Xia, E. Q.; He, T. P.; Huang, M. Y.; Jia, Q.; Li, H. W. Ultrasound-assisted extraction of mangiferin from mango (Mangifera indica L.) leaves using response surface methodology. Molecules, 2014, 19 (2), 1411-1421. doi.org/10.3390/molecules19021411.

[13] Núñez-Sellés, A. J. (2011). The Challenge of Antioxidant Therapy. Editorial Académica Española, Madrid, Spain. 208 pp. ISBN 978-3846565995 (spanish).

[14] Nuñez Selles, A. J.; Velez Castro, H.; Agüero Agüero, J.; Gonzalez Gonzalez, J.; Naddeo, F.; De Simone, F.; Rastrelli, L. Isolation and Quantitative Analysis of Phenolic Antioxidants, Free Sugars, and Polyols from Mango (Mangifera indica L.) Stem Bark Aqueous Decoction Used in Cuba as Nutritional Supplement. J. Agric. Food Chem., 2002, 50, 762-766. doi.org/10.1021/jf011064b.

[15] Núñez-Sellés, A. J.; Delgado-Hernández, R.; Garrido-Garrido, G.; García-Rivera, D.; Guevara-García, M.; Pardo-Andreu, G. L. The paradox of natural products as pharmaceuticals: Experimental evidences of a mango stem bark extract. Pharmacol. Res., 2007, 55 (5), 351-358. doi.org/10.1016/j.phrs. 2007.01.004.

[16] Pardo-Andreu, G. L.; Sanchez-Baldoquin, C.; Avila-Gonzalez, R.; Delgado, R.; Naal, Z.; Curti, C. Fe(III) improves antioxidant and cytoprotecting activities of mangiferin. Eur. J. Pharmacol. 2006, 547: 31-6. doi.org/10.1016/j.ejphar.2006.07.040.

[17] Núñez Sellés, A. J.; Durruthy Rodríguez, M. D.; Rodríguez Balseiro, E.; Nieto González, L.; Nicolais, V.; Rastrelli, L. Comparison of major and trace element concentrations in 16 varieties of Cuban mango stem bark (Mangifera indica L.). J. Agric. Food Chem, 2007, 55 (6), 2176-2181. doi.org/10.1021/jf063051+.

[18] Rodríguez, J.; Di Pierro, D.; Gioia, M.; Monaco, S.; Delgado, R.; Coletta, M.; Marini, S. Effects of a natural extract from Mangifera indica $\mathrm{L}$, and its active compound, mangiferin, on energy state and lipid peroxidation of red blood cells. Biochim. Biophys. Acta Gen. Subj., 2006, 1760 (9), 1333-1342. doi.org/10.1016/j.bbagen.2006.04.005.

[19] Coelho, E. M.; de Souza, M. E. A. O.; Corrêa, L. C.; Viana, A C.; de Azevêdo, L. C.; dos Santos Lima, M. Bioactive compounds and antioxidant activity of mango peel liqueurs (Mangifera indica L.) produced by different methods of maceration. Antioxidants, 2019, 8 (4), 102. doi: 10.3390/antiox 8040102 .

[20] Noratto, G. D.; Bertoldi, M. C.; Krenek, K.; Talcott, S. T.; Stringheta, P. C.; Mertens-Talcott, S. U. Anticarcinogenic
Effects of Polyphenolics from Mango (Mangifera indica) Varieties. J. Agric. Food Chem. 2010, 58 (7), 4104-4112. doi.org/10.1021/jf903161g.

[21] Luo, F.; Lv, Q.; Zhao, Y.; Hu, G.; Huang, G.; Zhang, J.; Chen, $\mathrm{K}$. Quantification and purification of mangiferin from Chinese mango (Mangifera indica $\mathrm{L}$.) cultivars and its protective effect on human umbilical vein endothelial cells under $\mathrm{H} 2 \mathrm{O} 2-$ induced stress. Int. J. Mol. Sci., 2012, 13 (9), 11260-11274. doi.org/10.3390/ijms130911260.

[22] Zheng, M. S.; Lu, Z. Y. Antiviral effect of mangiferin and isomangiferin on herpes simplex virus. Chin. Med. J., 1990, 103 (2), 160-165. PMID: 2167819.

[23] Toop, T. A.; Ward, S.; Oldfield, T.; Hull, M.; Kirby, M. E.; Theodorou, M. K. AgroCycle-developing a circular economy in agriculture. Energy Proc., 2017, 123: 76-80. doi.org/10.1016/j.egypro.2017.07.269.

[24] Morais, A. R.; Bogel-Lukasik, R. Green chemistry and the biorefinery concept. Sustain. Chem. Proceed., 2013, 1 (1), 18. doi.org/10.1186/2043-7129-1-18.

[25] Bocken, N. M.; De Pauw, I.; Bakker, C.; van der Grinten, B. Product design and business model strategies for a circular economy. J. Ind. Prod. Eng., 2016, 33 (5), 308-320. doi.org/10.1080/21681015.2016.1172124.

[26] Schieber, A.; Carle, R. By-products from mango (Mangifera indica L.) processing as a source of functional compounds. In Proceedings "Tropical Fruits in Human Nutrition and Health" Queensland, Australia, 2008, p. 67-74. http://era.daf.qld.gov.au/id/eprint/1553/1/4549 Tropical fruit c onference_proceedings_v2.pdf(Accessed on Sept. 25th, 2020).

[27] Dorta, E.; Lobo, M. G.; González, M. Optimization of factors affecting extraction of antioxidants from mango seed. Food Bioproc. Technol., 2013, 6 (4), 1067-1081. doi.org/10.1007/s11947-011-0750-0.

[28] Velderrain-Rodríguez, G.; Torres-Moreno, H.; VillegasOchoa, M. A.; Ayala-Zavala, J. F.; Robles-Zepeda, R. E.; Wall-Medrano, A.; González-Aguilar, G. A. Gallic acid content and an antioxidant mechanism are responsible for the antiproliferative activity of 'Ataulfo' mango peel on LS180 cells. Molecules, 2018, 23 (3), 695. doi: 10.3390/molecules 23030695 .

[29] Banerjee, J.; Singh, R.; Vijayaraghavan, R.; MacFarlane, D.; Patti, A. F.; Arora, A. Bioactives from fruit processing wastes: Green approaches to valuable chemicals. Food Chem., 2017, 225, 10-22. doi.org/10.1016/j.foodchem.2016.12.093.

[30] Matos, M. S.; Romero-Diez, R.; Álvarez, A.; Bronze, M. R.; Rodríguez-Rojo, S.; Mato, R. B.; Cocero, M. J.; Matias, A. A. Polyphenol-rich extracts obtained from winemaking waste streams as natural ingredients with cosmeceutical potential. $\begin{array}{lllll}\text { Antioxidants, } & 2019, & 8 & \text { (9), } & 355 .\end{array}$ doi.org/10.3390/antiox8090355.

[31] Panzella, L.; Moccia, F.; Nasti, R.; Marzorati, S.; Verotta, L.; Napolitano, A. Bioactive phenolic compounds from agri-food wastes: An update on green and sustainable extraction methodologies. Front. Nutr., 2020, 7, 60. doi.org/10.3389/fnut.2020.00060.

[32] Akhtar, S.; Ismail, T.; Fraternale, D.; Sestili, P. Pomegranate peel and peel extracts: Chemistry and food features. Food Chem., 2015, 174, 417-425. doi.org/10.1016/j.foodchem.2014.11.035. 
[33] Sánchez, G. M.; Re, L.; Giuliani, A.; Nuñez-Selles, A. J.; Davison, G. P.; Leon-Fernandez, O. S. Protective effects of Mangifera indica L. extract, mangiferin and selected antioxidants against TPA-induced biomolecules oxidation and peritoneal macrophage activation in mice. Pharmacol. Res., 2000, 42 (6), 565-573. doi.org/10.1006/phrs.2000.0727.

[34] Nuñez Selles, A. J.; Villa, D. G.; Rastrelli, L. Mango polyphenols and its protective effects on diseases associated to oxidative stress. Curr. Pharm. Biotechnol., 2015, 16 (3), 272280. doi.org/10.2174/138920101603150202143532.

[35] Hou, S.; Wang, F.; Li, Ying.; Li, Y.; Wang, M.; Sun, D.; Sun, S. Pharmacokinetic study of mangiferin in human plasma after oral administration. Food Chem., 2012, 132, 289-294. doi.org/10.1016/j.foodchem.2011.10.079.

[36] Imran, M.; Arshad, M. S.; Butt, M. S.; Kwon, J. H.; Arshad, M. U.; Sultan, M. T. Mangiferin: a natural miracle bioactive compound against lifestyle related disorders. Lip. Health Dis., 2017, 16 (1), 84-100. doi.org/10.1186/s12944-017-0449-y.

[37] Yang, S.; Zhou, Q.; Zhang, B.; Zhang, L.; Yang, D.; Yang, H.;
Du, G.; Lu, Y. Screening, Characterization and Evaluation of Mangiferin Polymorphs. Nat. Prod. Bioprospect., 2020, 10 (4), 187-200. doi.org/10.1007/s13659-020-00247-z.

[38] Nuñez Selles, A. J.; Daglia, M.; Rastrelli, L. The potential role of mangiferin in cancer treatment through its immunomodulatory, antiangiogenic, apoptopic and gene regulatory effects. Biofactors, 2016, 42 (5), 475-491. doi.org/10.1002/biof.1299.

[39] Berardini, N.; Carle, R.; Schieber, A. Characterization of gallotannins and benzophenone derivatives from mango (Mangifera indica L. cv.'Tommy Atkins') peels, pulp and kernels by high-performance liquid chromatography/electrospray ionization mass spectrometry. Rap. Comm. Mass Spectrom., 2004, 18 (19), 2208-2216. doi.org/10.1002/rcm.1611.

[40] Navarro, M.; Arnaez, E.; Moreira, I.; Quesada, S.; Azofeifa, G.; Wilhelm, K.; Vargas, F.; Chen, P. Polyphenolic Characterization, Antioxidant, and Cytotoxic Activities of Mangifera indica Cultivars from Costa Rica. Foods, 2019, 8 (9), 384. doi.org/10.3390/foods8090384. 